\title{
"Para que poucos usufruam muito, muitos não devem usufruir nada": movimentos de voz e saída no filme "in time"
}

"For a few to enjoy a lot, many must enjoy nothing": voice and exit movements in the movie "in time"

João Paulo Baliscei', Geiva Carolina Calsaii, Vinícius Stein ${ }^{\mathrm{iii}}$ Universidade Estadual de Maringá

\section{Resumo}

Neste artigo o objetivo é discutir sobre predicativos da sociedade contemporânea globalizada cujo alicerce é estruturado sobre o capital e a cultura. Para tanto, desenvolveu-se uma pesquisa documental sobre o filme In Time (2011), ficção que diz respeito a uma sociedade organizada através do tempo e do dinheiro. Utilizou-se do Image Watching (OTT, 2011) como ferramenta de análise, aproximando o corpus de conceitos de Bauman (2007; 2010), Bourdieu (1989; 2014) e Hirschman (1979). Considerou-se que, em uma economia alicerçada no consumismo, como a da ficção e a da contemporaneidade, a produtividade, o descarte, a distribuição assimétrica de bens e a dominação são estratégias que operam a manutenção do capitalismo.

Palavras-chave: contemporaneidade, poder simbólico, violência simbólica, modernidade líquida, estudos culturais.

\section{Abstract}

In this article, the aim is to discuss some features of the globalized contemporary society whose foundation is structured on capital and culture. To do so, we developed a documental research on the movie In Time (2011), fiction regarding a society organized by time and money. We used Image Watching (OTT 2011) as an analytical tool, approximating the corpus of concepts by Bauman (2007; 2010), Bourdieu (1989; 2014), and Hirschman (1979). We found that, in an economy rooted in consumerism, such as the one of fiction and contemporaneity, productivity, disposal, asymmetric distribution of goods and domination are strategies that operate the maintenance of capitalism.

Keywords: contemporaneity, symbolic power, symbolic violence, liquid modernity, cultural studies.

Revista Digital do LAV - Santa Maria - vol. 9, n. 2, p. 167 - 180. - mai./ago. 2016 ISSN 1983 - 7348 http://dx.doi.org/10.5902/1983734822296 


\title{
Tempo é dinheiro: A sociedade capitalista e os caminhos da pesquisa científica
}

\author{
"Vou \\ Uma vez mais \\ Correr atrás \\ De todo o meu tempo perdido \\ Quem sabe, está guardado \\ Num relógio escondido por quem \\ Nem avalia o tempo que tem". \\ (Trechos de Um tempo que passou, música de Chico Buarque) ${ }^{1}$
}

Após a Revolução Industrial, o sistema de mercado e a produção de bens materiais físicos e simbólicos conduziu o mundo e a organização social a um nível de conforto que, em outros tempos, seria considerado inalcançável. A produtividade e a eficiência das máquinas, assim como o desenvolvimento tecnológico, alargaram os limites e aumentaram as condições de consumo de indivíduos de países industrializados. A fronteira que divide o que é acessível e o que não é, o que pode ser consumido e o que não pode, é cada vez mais tênue e, como consequência disso, mais do que a segurança e a estabilidade, são os movimentos irregulares e bruscos do mercado que balizam as ações, empregos, preferências e pensamentos dos individuais e coletivos.

De acordo com Bauman (2010), o sistema capitalista tem caráter parasitário e predatório haja vista que busca espaços "virgens" e exploráveis para extrair deles sustâncias que subsidiem sua nutrição existencial e individual. Destarte, o/a parasita executa o processo de sondagem no/a hospedeiro/a, planejando a melhor forma de adequação e de apropriação daquilo que lhe é conveniente. A partir disso, preocupamonos com a procura insaciável que o capitalismo parasitário tem por possíveis predadores/as na medida em que as fontes se esgotam em número, energia e qualidade.

Em uma sociedade capitalista, quais os papéis e espaços desempenhados pelo poder material e simbólico? Como o dinheiro e o tempo, combinados, balizam as organizações, pensamentos e comportamentos dos indivíduos contemporâneos? Neste artigo, nosso objetivo é discutir sobre predicativos da sociedade contemporânea globalizada cujo alicerce é estruturado sobre o capital e a cultura. Nossa intenção em considerar a cultura (e não apenas o capital) como categoria sobre a qual a sociedade pode ser analisada foi a de buscar,

\footnotetext{
1 Consideramos que essa música auxilia-nos na compreensão da relação entre tempo, vida e consumo. A letra completa, assim como o clipe da música podem ser localizados no link <http://www.vagalume.com.br/chico-buarque/um-tempo-que-passou.html>. Acesso em 21 de setembro de 2015.
}

Revista Digital do LAV - Santa Maria - vol. 9, n. 2, p. 181- 201. - mai./ago. 2016 ISSN 1983 - 7348 http://dx.doi.org/10.5902/1983734822296 
[...] meios de escapar da ruinosa alternativa entre o "material" e o "espiritual" ou "ideal" (mantida atualmente por meio da oposição entre os estudos ditos "materialistas", que explicam a assimetria [...] pelas condições de produções, e os estudos ditos "simbólicos", muitas vezes notáveis, porém parciais). (BOURDIEU, 2014, p. 13).

Desta maneira, assim como o autor, consideramos o capital e a cultura como produtores das relações, vínculos, lutas, alteridades e assimetrias sociais. Para desempenharmos o objetivo proposto nesse artigo, desenvolvemos uma pesquisa documental, entendendo como documento "[...] qualquer tipo de registro histórico fotos, diários, arte, música, entrevistas, depoimentos, filmes, jornais, revistas, sites e outros" (EVANGELISTA, 2009, p.1). Os pressupostos teórico-metodológicos apontados pela autora auxiliaram-nos na escolha do filme In Time (O Preço do Amanhã, 2011), de Andrew Niccol (1964 --), como documento de análise dessa pesquisa, haja vista que este trata de questões de trabalho e conflitos entre indivíduos de classes sociais distintas e estabelece relações diretas entre tempo e dinheiro. Nessa ficção, enquanto grupos lutam para garantir a sobrevivência diária, outros grupos ostentam o excesso de riqueza que conquistaram por meio do abuso dos/as trabalhadores/as menos favorecidos/as. Além disso, diz respeito a uma sociedade que, semelhante a essa em que vivemos, é organizada através do tempo e do dinheiro: vive-se, trabalha-se, consome-se e movimenta-se por e para eles. Em In Time (2011), tempo literalmente é dinheiro.

Conforme Evangelista (2009, p.7), os documentos sozinhos, estanques, são desprovidos de significados e cabe ao pesquisador ou pesquisadora, em sua investigação, "[...] encontrar o sentido dos documentos e com eles construir conhecimentos". No que tange às análises de documentos visuais é relevante destacar que os significados não "emanam" das imagens, mas sim do indivíduo que se relaciona com elas, neste caso, o/a pesquisador/a (BALISCEI, 2014; BALISCEI; STEIN, 2015).

Seguindo essas premissas, para investigar o corpus de análise, constituído por cinco cenas, compostas por 21 imagens do longa-metragem ${ }^{2}$, utilizamos como ferramenta metodológica o sistema de análise de imagem Image Watching, desenvolvido por Ott (2011). O Image Watching é composto por cinco etapas - Descrevendo, Analisando, Interpretando, Fundamentando e Revelando - que consistem em ações de estudos específicos de documentos visuais, tais como produções da História da Arte, publicidades e imagens cinematográficas. Compreendemos que as ações específicas e direcionados do Image Watching (OTT, 2011) contribuem para que o pesquisador ou pesquisadora "[...] assuma uma posição ativa na produção de conhecimento: localiza, seleciona, lê, relê, sistematiza, analisa as evidências que apresenta" (EVANGELISTA, 2009, p. 5).

${ }^{2} \mathrm{O}$ termo se refere a produções fílmicas cuja duração é superior a 70 minutos. 
"Para que poucos usufruam muito, muitos não devem usufruir nada": movimentos de voz e saída no filme "in time"

Quanto à estrutura do presente artigo, desenvolvemos esta reflexão em três partes. No primeiro momento, apresentamos os conceitos de Modernidade Líquida, Guetos Voluntários, Guetos Involuntários, Mixofobia e Mixofilia (BAUMAN, 2007; 2010), predicativos da sociedade contemporânea, marcada pela globalização, pelo capitalismo e pela aceleração do tempo - constantemente associado ao consumo e ao dinheiro. Além disso, debruçamo-nos sobre os conceitos de Poder Simbólico e Violência Simbólica (BOURDIEU; 1989; 2014), aproximando-os do cotidiano líquido-moderno.

Em um segundo momento, retomamos aspectos de nossa ferramenta de análise de imagens, o Image Watching (OTT, 2011), especificando suas cinco etapas. Por fim, em um terceiro momento, antes de tecermos nossas considerações finais, localizamos, nas cenas, falas e narrativas do filme In Time (2011), divergências e/ou convergências com os conceitos anteriormente citados, acrescentados aos de Saída e Voz (HIRSCHMAN, 1979).

\section{De onde falamos: 0 tic-tac do relógio líquido-moderno}

Bauman (2007, 2010) afirma que vivenciamos uma condição social denominada de Modernidade Líquida. Líquida porque é congruente aos aspectos físico-químicos da volatilidade, velocidade e flexibilidade dos componentes. Esta é uma condição em que organizações controladoras e instituições que apontam para comportamentos ideais e padrões aceitáveis, como as igrejas, famílias e escolas, não conseguem manter sua forma a longo prazo - como também não se espera que o façam. Em uma sociedade líquido-moderna, em que as relações são formadas não por estruturas cujas bases são sólidas, mas por redes de conexões e desconexões entre os indivíduos, nada permanece por muito tempo em seu lugar de origem.

$\mathrm{Na}$ modernidade líquida, os indivíduos procuram estabelecer afinidades que colaborem para a manutenção e fomento de seus desejos materiais e satisfações provisórias, calcadas na livre escolha e no consumismo. Embora a vida globalizada auxilie no (re)conhecimento de diversas manifestações culturais e no desenraizamento de conceitos estabelecidos entre determinados grupos, é possível perceber que ainda existem intensos movimentos para a formação de uma sociedade dividida por questões individualistas e pela insegurança. Em outras palavras, em uma sociedade formada por vínculos humanos frouxos, oportunos e quebradiços, em que a individualidade e o egoísmo são apresentados como condições obrigatórias, cada vez mais torna-se difícil (se não impossível) praticar a solidariedade e a conscientização dos benefícios do coletivo.

Assim, o senso de unidade bradado pela globalização não significa que os indivíduos se organizarão coletivamente, em prol da igualdade e do bem estar social, mas que dificilmente escaparão às vivências das relações de (des)vantagens. Presume-se

Revista Digital do LAV - Santa Maria - vol. 9, n. 2, p. 181- 201. - mai./ago. 2016 ISSN 1983 - 7348 http://dx.doi.org/10.5902/1983734822296 
então que as "[...] lógicas da sociedade de consumo são inescapáveis" (MOMO, 2015, p. 111).

Em uma sociedade constituída por grupos que, antes fechados, isolados, agora estão abertos ao livre mercado e interligados por uma rede de indivíduos consumidores traz à tona a ideia de vulnerabilidade das fronteiras. Tendo em vista a instituição de mecanismos para "[...] minimizar tanto o raio de ação do Estado em sentido estrito na vida da sociedade como seu papel na condução dessa sociedade" (MELO; FALLEIROS, 2005, p. 175), essa parcela significativa da população que está voltada gradualmente para o consumo sente a necessidade de garantir sua autoproteção e de seus e suas semelhantes.

Aterrorizados/as pela ideia de possíveis invasores/as, ladrões/ãs e outras ameaças externas, aqueles/as com posse de bens suficiente para "comprar" (e garantir) tal proteção, criam muros, obstáculos e barreiras para se afastarem dos/as que não a têm, potencializando injustiças, temores e preconceitos, já que, como destaca Bauman (2007, p. 15) "[...] os medos nos estimulam a assumir uma ação defensiva". Nas cidades, por exemplo, o autor acredita que existe a formação de uma complexa composição urbana em que aqueles/as movidos/as pelo medo constroem suas casas entre muros e cercas, afastando-se da vida em sociedade com os/as demais, considerados/as como "diferentes". O autor se refere a estas construções como Guetos Voluntários, termo que caracteriza aglomerações em que os/as moradores/as decidem transformar suas residências e espaços supostamente coletivos em lugares privados, agradáveis e, ao mesmo tempo, aparentemente livres de ameaças desconhecidas.

A principal característica dos guetos voluntários é que esta prática não só aparta os indivíduos que a aderem do convívio urbano, das questões sociais, das relações empáticas entre habitantes locais tidos como "diferentes" ou "indesejáveis", como tenta torna inviável o acesso daqueles/as que não possuem bens para a garantia de sua própria proteção. Por sua vez, sem usufruir de tal proteção, a camada popular da sociedade é responsável por dedicar seu trabalho a oferecer tais benefícios aos/às moradores/as (privilegiado/as) dos guetos voluntários.

Enquanto certos indivíduos podem usufruir de luxos, viagens, bens materiais, proteção, lazer e cultura, outros mantêm-se focados em necessidades diárias, imediatas e pontuais de sobrevivência. Com isso, estes últimos sujeitos são forçados a permanecerem naquilo que Bauman (2007) denomina de Guetos Involuntários que, em geral, são definidos por pessoas que integram os guetos voluntários, como lugares sem lei, abertos, inseguros, desprotegidos, caóticos e habitados por supostos/as criminosos/as. Os muros (sólidos e/ou simbólicos) que separam sujeitos de diferentes classes, culturas, religiões, gostos, gênero e sexualidade promovem o preconceito, o 
"Para que poucos usufruam muito, muitos não devem usufruir nada": movimentos de voz e saída no filme "in time"

medo daquilo que é desconhecido, do/a diferente, do/a estranho/a, reafirmando ao que Bauman (2007) se refere como Mixofobia.

O conceito de mixofobia está estruturado no fato de as pessoas procurarem estabelecer contato apenas com aqueles/as que julgam ser semelhantes, evitando a convivência com estranhos/as, desconhecidos/as, com quem thes é diferente e que, supostamente, potencializa o medo e a criação de guetos voluntários. Em nossa análise, este comportamento mixofóbico adia e evita promover reflexões sobre questões sociais das minorias e da diversidade cultural.

Nessa linha de raciocínio, é interessante mencionar que, de maneira semelhante a fomentação da mixofobia - esse conjunto de ações que "repelem" os/as "diferentes"- a vida nas cidades pode promover também a empatia entre os indivíduos, estimulando o que Bauman (2007) chama de Mixofilia. Nas palavras do autor,

A mixofobia que assombra a convivência dos moradores das cidades não é fonte de sua ansiedade, mas um produto de uma perversa e enganosa interpretação de suas fontes; [...] É a mixofilia, tão estranhada na vida urbana quanto sua oposição mixofóbica, que carrega um germe de esperança: não apenas a esperança de tornar a vida urbana [...] menos preocupante e mais fácil, mas também a de aliviar as tensões que surgem, por motivos similares, em escala planetária. (BAUMAN, 2007, p. 97-98).

Mixofobia e mixofilia são consideradas comportamentos ambivalentes, que se complementam e parecem ser perpetuados na atual concepção de sociedade líquidomoderna. Quando debruçamo-nos sobre esses conceitos, evidenciamos aproximações com aquilo que Bourdieu (1989) denomina como Poder Simbólico, isto é, um poder velado, "invisível" que é exercido a partir da cumplicidade e indiferença, ainda que inconsciente, daqueles/as que o exercem e daqueles/as que lhe estão sujeitos/as.

A cultura dominante contribui para a integração real da classe dominante (assegurando uma comunicação imediata entre todos os seus membros e distinguindo-os das outras classes); para a integração fictícia da sociedade em seu conjunto, portanto, à desmobilização (falsa consciência) das classes dominadas; para a legitimação da ordem estabelecida por meio do estabelecimento das distinções (hierarquias) e para a legitimação dessas distinções. (BOURDIEU, 1989, p. 10).

Frente a isso, consideramos que a mixofobia é produto e produtora de poder simbólico, quando os indivíduos operantes de suas relações demonstram aceitação, conformismo ao status quo, ou, mais agravante, desprendimento e indiferença às ações e pensamentos capazes de transformar a sociedade. Nessa perspectiva, elabora-se o que Bourdieu (1989) denomina como Violência Simbólica, sistemas simbólicos cuja função é assegurar e garantir que determinados grupos sejam favorecidos e que a dominação

Revista Digital do LAV - Santa Maria - vol. 9, n. 2, p. 181- 201. - mai./ago. 2016 ISSN 1983 - 7348 http://dx.doi.org/10.5902/1983734822296 
sobre outros grupos seja perpetuada. Bourdieu (2014) a caracteriza pela suavidade, insensibilidade e invisibilidade, inclusive, para suas próprias vítimas que acabam por naturalizá-la, como se fossem inquestionáveis e, por isso, são também coniventes à violência simbólica.

Quando os dominados aplicam àquilo que os domina esquemas que são produtos da dominação, ou, em outros termos, quando seus pensamentos e suas percepções estão estruturadas de conformidade com as estruturas mesmas da relação da dominação que lhes é imposta, seus atos de conhecimento são, inevitavelmente, atos de reconhecimento, de submissão. (BOURDIEU, 2014, p. 27, grifo do autor).

Desta maneira, quando se legitimam os movimentos e a hierarquia da dominação, sendo repercutidos e, mais do que isso, reproduzidos em demais organizações, como as familiares, as midiáticas, as escolares, elabora-se um padrão ao qual Bourdieu (2014) se refere como Consagração Simbólica, que consiste na falta de resistência, na passividade e na aceitação da dominação, tanto por parte dos/as dominantes, como dos/as dominados/as.

Conforme recorremos aos conceitos de Modernidade Líquida, Guetos Voluntários e Guetos Involuntários, Mixofobia e Mixofilia, Poder Simbólico, Violência Simbólica e Consagração Simbólica, reconhecemo-los em nossas vivências cotidianas e na organização social. A compreensão da problemática causada pelo movimento de atração e repulsão das classes sociais e entre aqueles que se consideram "diferentes", torna-se mais acessível quando nos propomos a analisar a produção cinematográfica In Time (2011). Por meio da análise das cenas desse filme, podemos refletir sobre as possíveis causas e consequências da (des)continuidades do sistema capitalista, além de discutir sobre predicativos da sociedade contemporânea globalizada cujo alicerce é estruturado sobre o capital e a cultura.

\section{Instrumentalizando a análise: 0 Image Watching e o olhar pesquisador}

Para a análise do filme In Time (2011), apropriamo-nos do sistema de análise de imagem Image Watching, de Robert William Ott (2011), desenvolvido inicialmente no âmbito pedagógico para análise de arte em museus. Para discutir sobre predicativos da sociedade contemporânea globalizada cujo alicerce é estruturado sobre o capital e a cultura, nesse artigo, optamos por relacionar cenas do filme aos conceitos de Bauman (2007; 2010); Bourdieu (1989; 2014) e Hirschman (1979), apresentados por nós anteriormente. Antes disso, primeiramente, discutimos sobre o Image Watching.

O Image Watching, que pode ser traduzido como Assistindo ou Observando Imagens, trata-se de um sistema de análise de imagem constituído por cinco etapas - 
"Para que poucos usufruam muito, muitos não devem usufruir nada": movimentos de voz e saída no filme "in time"

Descrevendo, Analisando, Interpretando, Fundamentando e Revelando - que atuam como procedimentos de estudo específicos. Em Descrevendo, são apontados os elementos que podem ser visualmente percebidos na composição. Em Analisando, estabelecemos relações entre esses elementos, comparando-os. Além disso, podemos identificar a técnica da produção e investigar os elementos formais ${ }^{3}$ que compõem a imagem. Em Interpretando, são tecidas impressões pessoais, respaldadas no repertório cultural de cada indivíduo que busca atribuir significados à imagem. Fundamentando consiste na etapa de busca e pesquisa, em que referenciais teóricos e outros documentos operam como mediadores para ampliar e complementar os conhecimentos elaborados. Por fim, Revelando, quinta e última etapa do Image Watching, é o momento de, por meio de uma produção, no nosso caso, textual, demonstrarmos os conhecimentos produzidos nas etapas anteriores.

Ott (2011) observa que, embora o Image Watching seja um sistema que siga determinada ordem, cada categoria não se conclui em si, pois a análise é feita de forma geral, sendo impossível dissociá-las. Somado a isso, o campo de investigação a partir de onde (re)formulamos e emitimos nossos olhares - os Estudos Culturais - incentivam-nos a criar e experimentar métodos e metodologias de pesquisa para além dos tradicionais. Dito isso, é importante esclarecer que, afirmar que os Estudos Culturais não possui metodologia(s) e método(s) próprios e específicos não é o mesmo que dizer que aprovam um "vale tudo metodológico". Não é isso.

Quando estimulam o desenvolvimento e a problematização de metodologias os Estudos Culturais exploram o potencial de criação do/a pesquisador/a e, assim como as teorias pós-estruturalistas, marcadas, sobretudo, pelo feminismo, compreendem que pesquisar não é nunca um processo frio, racional e unicamente técnico. Ao contrário disso, para esses campos de estudos, pesquisar, como destaca Steinberg (2015) envolve os sentimentos, a subjetividade e as experiências de quem pesquisa.

[...] procurando distinguir-se como um campo de estudo pela forma como se relacionam com a teoria e sua aplicação -, os EC [Estudos Culturais] se servem de um conjunto de métodos desenvolvidos no bojo da tradição acadêmica, modificando-os e adaptando-os de acordo com intenções de estudos que extrapolam credenciais disciplinares. (KIRCHOF, et al, 2015, p. 10)

Desta forma, respaldamo-nos nos Estudos Culturais para utilizar de formas criativas e ousadas na investigação, readaptando as etapas do Image Watching (OTT, 2011). Em nossa análise do filme In Time (2011), as cinco etapas do Image Watching não foram fragmentadas e, muito menos, seguem uma ordem rígida e linear de execução. Tendo em vista aspectos práticos e didáticos, preferimos sobrepor as três

${ }^{3}$ Elementos que estruturam a composição de uma figura, tal como ponto, linha, cor, movimento, textura, harmonia e proporção (DONDIS, 2000).

Revista Digital do LAV - Santa Maria - vol. 9, n. 2, p. 181- 201. - mai./ago. 2016 ISSN 1983 - 7348 http://dx.doi.org/10.5902/1983734822296 
primeiras categorias - Descrevendo, Analisando e Interpretando; na etapa Fundamentando relacionamos as cenas com os conceitos apresentados anteriormente; e a etapa Revelando, por fim, acomete no presente artigo, haja vista que nele materializamos os conhecimentos elaborados nas etapas anteriores.

\section{In Time: 0 (alto) preço do Amanhã}

Muitos dos conceitos sobre os quais anteriormente discorremos podem ser identificados no filme In Time (2011). O filme de fiç̧ão científica, dirigido por Andrew Niccol, partilha da mesma natureza de embates entre vida humana e tecnologias complexas, presentes em outras produções do diretor como Gattaca (1997), que trata da eugenia e seus desdobramentos éticos, e S1m0ne (2002), em que a atriz Simone é materializada e controlada virtualmente pelo programa Simulation One (partindo daí sua denominação). Em In Time (2011), Andrew Niccol parece aludir à lógica da produção industrial capitalista. Uma consideração interessante a ser feita é em relação ao título do filme: na expressão americana, "In time" possui o significado de estar em tempo certeiro, adequado, que escapa ao esgotamento, do mesmo modo como pode significar estar imerso no tempo, participando dele.

In Time (2011) se desenrola em mais um universo paralelo de Andrew Niccol, e conta a história de como uma sociedade distópica se molda em um sistema, cuja moeda é o tempo - mostrado por meio de um cronômetro localizado no antebraço esquerdo dos habitantes locais. Segundos, minutos, horas, dias, semanas, meses, anos, décadas e séculos são algumas das medidas que sinalizam o poder aquisitivo dos indivíduos e, concomitantemente, denotam seu tempo de vida em contagem regressiva. Em outras palavras, tempo e dinheiro são substantivos equivalentes e, por isso, nesse artigo, para nos referirmos a eles, utilizamos o termo "capital/tempo de vida".

Nessa sociedade, ao completar 25 anos de idade, o sujeito para de envelhecer pelo menos geneticamente - e o cronômetro que possui em seu antebraço é acionado, com reserva de um ano, evidenciando perda de tempo e metaforicamente, de vida. Para se continuar vivendo, é preciso não permitir que o relógio zere, isto é, arranjar mais tempo. O tempo é adquirido por meio da herança, do roubo, das apostas e, sobretudo, por meio do trabalho. Além disso, Em In Time (2011), o país é dividido em zonas de tempo e a manutenção e controle desse sistema ficam a cargo dos guardiões do tempo, os timekeepers. Especificamente, o filme dá enfoque a duas zonas de tempo: Dayton, centro de manufatura de trabalhadores/as e New Greenwich, a mais rica das zonas, onde se comemoram as condições "imortais" sob o deleite, o prazer e a satisfação de uma vida sem preocupações imediatas.

Revista Digital do LAV - Santa Maria - vol. 9, n. 2, p. 181 - 201. - mai./ago. 2016 ISSN 1983 - 7348 http://dx.doi.org/10.5902/1983734822296 
"Para que poucos usufruam muito, muitos não devem usufruir nada": movimentos de voz e saída no filme "in time"

Will Salas ${ }^{4}$, o protagonista do filme, tem 28 anos e é um operário da cidade manufaturada de Dayton. Com o relógio acionado a três anos, encontra na baixa remuneração de seu trabalho meios para sobreviver. Em um bar local, Will Salas, com cerca de 19 horas de capital/tempo de vida em seu cronometro, depara-se com Henry Hamilton $^{5}$, um homem de posses que, na ocasião, está pagando bebidas a quem quisesse consumi-las. Se isso não fosse suficiente, Henry Hamilton atrai a atenção para seu antebraço e para seu cronômetro de incontáveis números: algo definitivamente não local. Will Salas o adverte em relação à gangue criminal que estava a caminho e que, possivelmente, poderia roubá-lo.

Surpreendido pelos criminosos que desejavam roubar-lhe capital/tempo de vida, Henry Hamilton é salvo por Will Salas e é levado para um local abandonado e escuro tomado por tons alaranjados, evidenciando a dramaticidade da cena. O típico burguês então confessa que tem 105 anos e que as centenas de anos que reservava no cronômetro de seu antebraço não faziam sentido algum. Por este motivo, submetera-se a uma situação suicida propositalmente. Henry Hamilton, mesmo com as posses está cansado, é um desvio da sociedade. Ele também esclarece que existem inúmeras estratégias para que as pessoas de zonas mais precárias continuem morrendo ou para que, ao menos permaneçam aonde estão. Essa lógica interessa e beneficia aqueles e aquelas que vivem em zonas mais ricas pois, como anunciado por Henry Hamilton, não há espaços no mundo para que todos/as vivam eternamente.

A frase que ajuda a compor o título desse artigo, "Para que poucos sejam imortais, muitos têm que morrer", é pronunciada por Henry Hamilton e converge com o sistema capitalista e com os conceitos de Bauman (2007; 2010), haja vista que, indivíduos de guetos involuntários - assim como os problemas que os caracterizam - são forçados a permanecerem locais.

Após esse diálogo, Will Salas cai no sono e Henry Hamilton aproveita a situação para aproximar seu braço-cronômetro ao dele, e transferir-lhe parte de seu capital/tempo de vida. Quando Will Salas acorda é surpreendido com 116 anos adicionais ao seu cronômetro e com um recado deixado à janela: "Não desperdice meu tempo". Após isso, Will Salas avista Henry Hamilton sentado à borda da ponte de onde cai, sem vida, assim que tem seu cronômetro "zerado". Neste mesmo instante, Will Salas é filmado pelas câmeras que rondam a cidade e então acusado de homicídio. A Figura.01 reúne algumas imagens que auxiliam na compreensão da cena que descrevemos.

\footnotetext{
${ }^{4}$ Personagem encenado por Justin Timberlake (1981--).

${ }^{5}$ Interpretado por Matt Bomer (1977 --)
} 


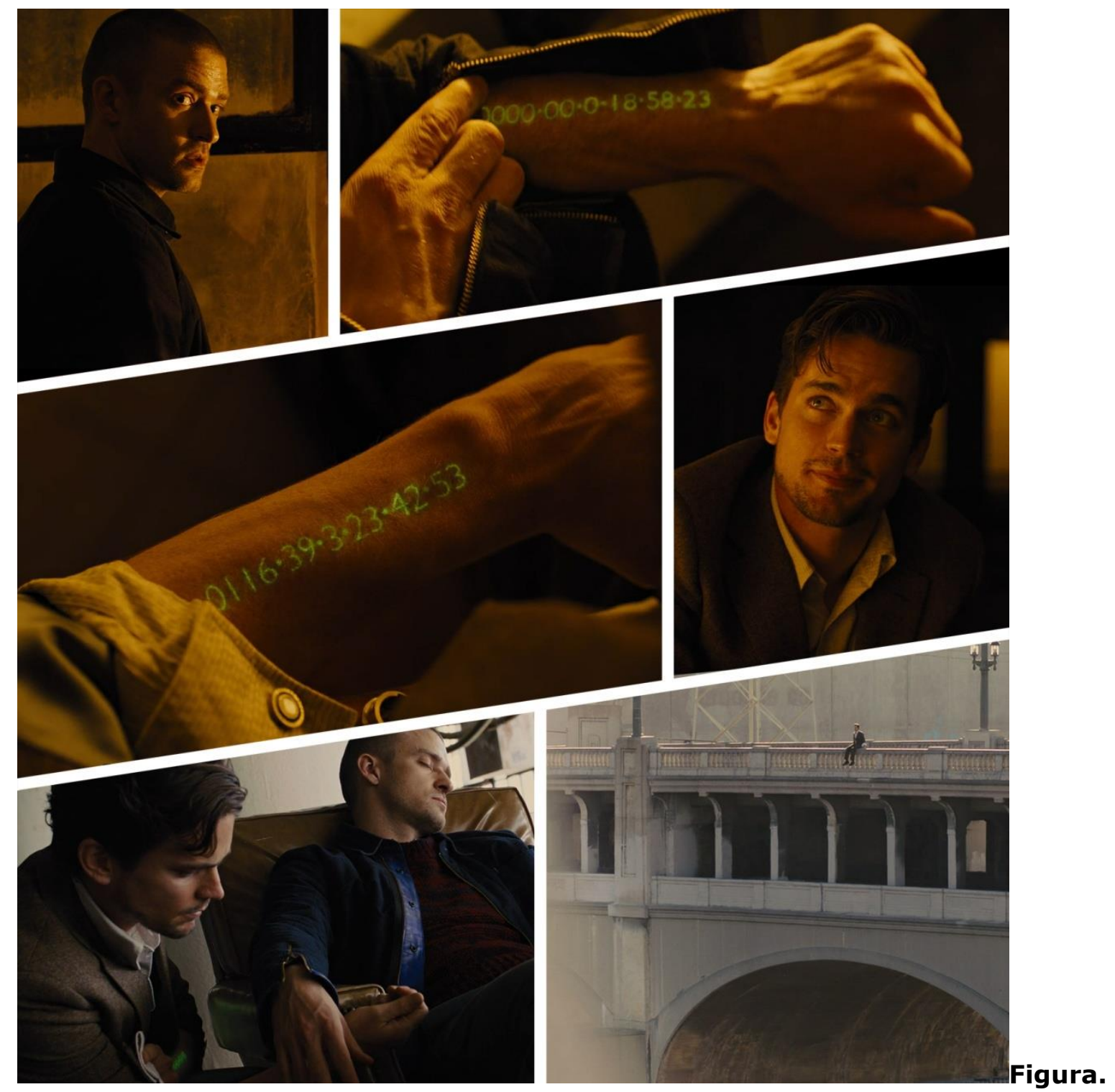

01: "Para que poucos sejam imortais, muitos têm que morrer"

Fonte: Prints Screen capturados entre o 12' e o 16' do vídeo localizado no YouTube pelo link: <https://www.youtube.com/watch?v=1vQYroOViBk>. Acesso em $21 \mathrm{de}$ setembro de 2015.

Duas das imagens que compõem a Figura.01 ilustram os cronômetros de Will Salas e Henry Hamilton, respectivamente e reforçam que, "A maioria das sociedades humanas é marcada pela existência de excedentes, ou seja, produção acima da necessária à subsistência" (HIRSCHMAN, 1979, p. 18), uma vez que, a média da soma do tempo de vida real de Will Salas (28 anos) e Henry Hamilton (105 anos), cerca de 67 anos, proporcionaria aos indivíduos condições pelo menos confortáveis de usufruírem de suas vidas e de adquirirem mais tempo. Todavia, como argumenta Hirschman (1979, p. 20), ainda que a sociedade como um todo produza excedente, vistas isoladamente, cada vida "[...] mal se sustenta, de maneira que um único passo em falso pode ser fatal". 
"Para que poucos usufruam muito, muitos não devem usufruir nada": movimentos de voz e saída no filme "in time"

As impressões do autor podem ser localizadas na vida de Will Salas que, diariamente, vive com algumas horas depositadas em seu cronômetro e ao passo que os algarismos se modificam regressivamente em seu antebraço, busca meios de economizar e adquirir mais capital/tempo de vida. Quando a divisão de capital/tempo de vida não é assimétrica, como demonstrado na Figura.01, pequenos grupos, representados por Henry Hamilton, ficam com excedente, enquanto que outros, integrados por indivíduos como Will Salas, sobrevivem com o pouco que têm.

No que tange à análise da cena a partir dos referenciais teóricos sobre os quais nos debruçamos, evidenciamos aproximação com o conceito de Violência Simbólica (BOURDIEU, 1989; 2014) já que, nessa sociedade fictícia, tanto dominantes quanto dominados/as parecem ter se acostumado com a divisão da sociedade em guetos voluntários e involuntários (BAUMAN, 2007; 2010). No diálogo entre os personagens verificamos que a ordem social estabelecida é respeitada, de maneira que as proibições, as obrigações e as assimetrias sociais não são questionadas. Inclusive para Will Salas, que não se beneficia com a ordem posta - muito pelo contrário, encontra-se na base da pirâmide social - parece não existir outra(s) maneira(s) de dividir o capital/tempo de vida se não aquela vigente. A esses movimentos de aceitação e de omissão, Bourdieu (2014) se refere como paradoxo do doxa, que consiste no fato de que

[...] a ordem estabelecida, com suas relações de dominação, seus direitos e suas imunidades, seus privilégios e suas injustiças, salvo uns poucos acidentes históricos, perpetue-se depois de tudo tão facilmente, e que condições de existência das mais intoleráveis possam permanentemente ser vistas como aceitáveis ou até mesmo como naturais. (BOURDIEU, 2014, p. 11)

Will Salas, que agora possui mais de um século em reserva em seu cronômetro, pega um táxi em direção à New Greenwich, a zona mais rica da sociedade. O motorista do taxi, respondendo ao chamado de Will Salas, logo destaca que normalmente não atende gente dessa localidade, ao que Will Salas replica que "estava perdido" e Ihe mostra o capital/tempo de vida que tem em seu cronômetro como atestado de sua riqueza e poder. Já que o país é dividido em zonas de tempo de acordo com a quantidade de suas reservas, as "fronteiras" só podem ser atravessadas sob depósito de uma quantidade específica de tempo, o que reforça a permanência de pessoas nos espaços em que nasceram. No filme, a cada "fronteira" atravessada, era necessário pagar pedágio em capital/tempo de vida.

Horas, dias, semanas, meses...Conforme Will Salas se deslocava ao encontro de New Greenwish, mais aumentava o valor do capital/tempo de vida cobrado por atravessar as fronteiras. Além desse aspecto, ao passo que Will Salas cruza as fronteiras, aproximando de seu destino, as paisagens são modificadas: construções modernas,

Revista Digital do LAV - Santa Maria - vol. 9, n. 2, p. 181- 201. - mai./ago. 2016 ISSN 1983 - 7348 http://dx.doi.org/10.5902/1983734822296 
fábricas e atmosfera acinzentada, aparentemente poluída insinuam tecnologia e progresso por parte de quem vive ali. A Figura.02 retrata os momentos em que o Will Salas toma o taxi para sair de Dayton e atravessa barreiras de pedágios de três Zonas do Tempo, indo em direção à New Greenwish.

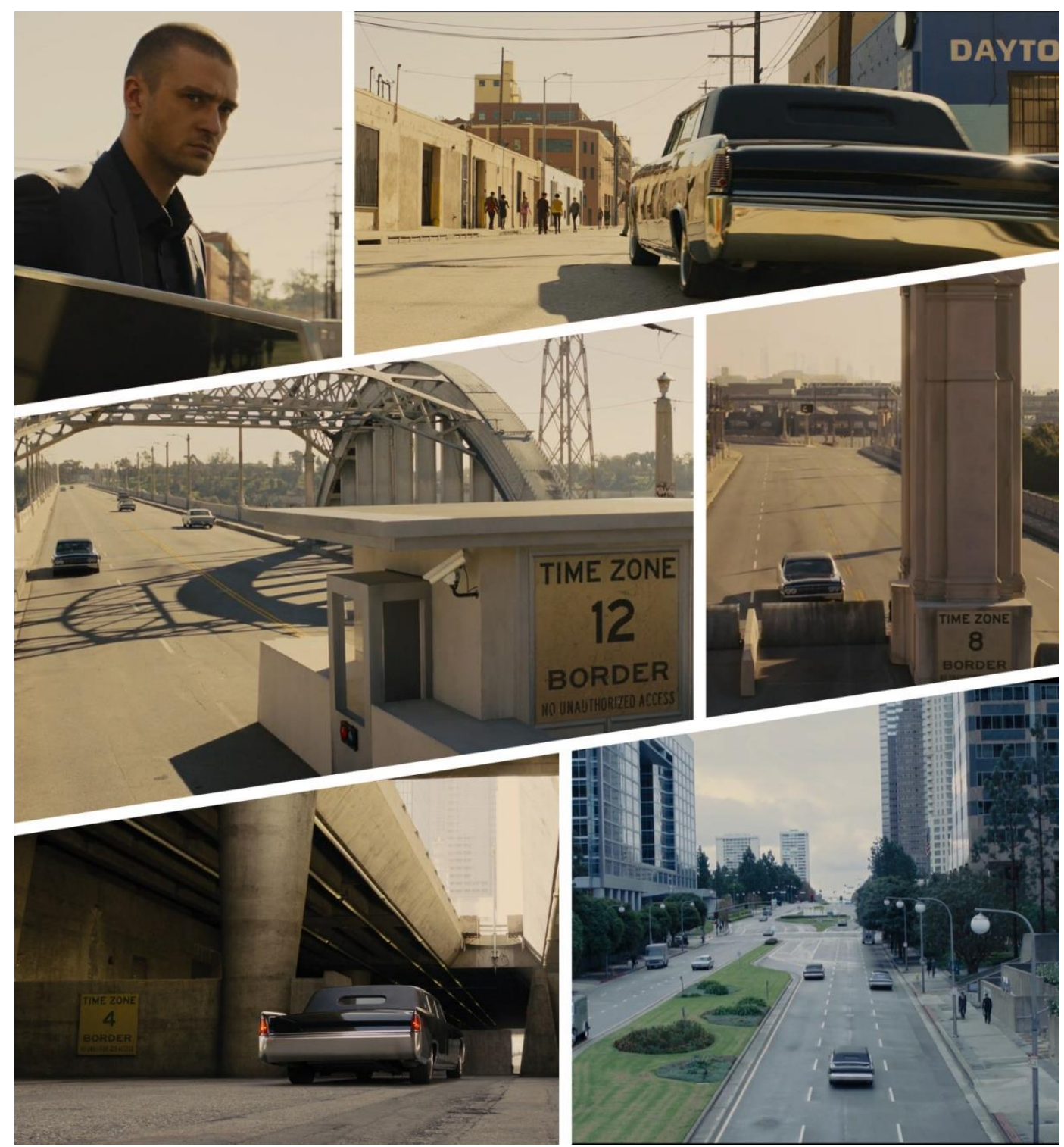

Figura.02: Atravessando fronteiras: Dayton, Zona 12, Zona 8 e Zona 04.

Fonte: Prints Screen capturados entre o 23' e o 26' do vídeo localizado no YouTube pelo link: <https://www.youtube.com/watch?v=1vQYrOOViBk>. Acesso em 21 de setembro de 2015.

Esse conjunto de cenas (Figura.02), assim como o valor dos pedágios pagos, a distância e a ideia de progresso auxiliam-nos na verificação daquilo que Bauman (2007) caracteriza como guetos voluntários e guetos involuntários. Apropriar-se demasiadamente da distância é uma das estratégias nas zonas urbanas para a manutenção desses guetos, pois, 
[...] os moradores com recursos compram casas em áreas separadas por eles escolhidas, também parecidas com guetos, impedem todos os outros de se fixarem nelas. Além disso, fazem o possível para desligar o mundo onde vivem daquele dos demais habitantes das cidades. (BAUMAN, 2007, p.79)

Por isso, caso estejam interessadas em atravessar as fronteiras, as pessoas precisam estar munidas de dinheiro, no caso do filme, capital/tempo de vida. Tanto na citação do autor quanto no filme, verificamos que as fronteiras são construídas e reforçadas por parte dos ricos e ricas com a intenção de propiciar o não vínculo com o resto da sociedade, isolando-se para não correr riscos de insegurança e abuso. Tanto os indivíduos da Modernidade Líquida, quanto os residentes da fictícia New Greenwish exercem a mixofobia (BAUMAN, 2007), já que são apavorados pela possibilidade de serem invadidos por estranhos/as que podem incomodá-los com seus problemas e conflitos, além de corromper o local seguro, agradável e com organização própria em que vivem.

Quando Will Salas chega ao seu destino e finalmente somos apresentados a New Greenwich e a seus/suas habitantes, observamos que as pessoas dessa cidade não correm como também não precisam fazê-lo, haja vista que possuem acúmulo de capital/tempo de vida. Mesmo com posse excedente de capital/tempo de vida, Will Salas não abandona seus costumes de agir com extrema rapidez, como comer com as mãos, já que fizera parte de uma sociedade onde os/as habitantes, sob o risco iminente de terem seus cronômetros zerados, estavam sempre acelerados/as. Numa sociedade em que capital e tempo de vida se sobrepõem, "[...] andar é melhor do que ficar sentado, correr é melhor do que andar, e surfar é ainda melhor do que correr" (BAUMAN, 2010, p.4546). Inclusive, o hábito acelerado de Will Salas, faz com que uma das garçonetes o perceba como "estrangeiro".

Em New Greenwich, Will Salas encontra Sylvia Weis ${ }^{6}$, filha do milionário Philippe Weis $^{7}$ e, diante de suas desigualdades socio-culturais, decide sequestrá-la e retornar a Dayton, como forma de equilibrar o sistema vigente.

Quando retornam a Dayton, a personagem Sylvia Weis se prontifica em vestir luvas para esconder o capital/tempo de vida que possui, evitando assim, que seja percebida e roubada pelos/as habitantes dessa zona periférica. Após sofrer um acidente de carro nessa zona desconhecida e insegura que é Dayton, quando retoma a consciência, Sylvia Weis verifica que foi assaltada e que, em seu antebraço esquerdo, o seu capital/tempo de vida havia diminuído de uma década ${ }^{8}$ para menos de uma hora. Apavorada ao perceber que Ihe restava meia hora de vida, Sylvia Weis, agora consciente,

\footnotetext{
${ }^{6}$ Interpretada por Amanda Seyfried (1985 --)

${ }^{7}$ Interpretado por Vincent Kartheiser (1979--)

${ }^{8}$ No filme, ao completar 25 anos, Sylvia herdara de seu pai a quantia de dez anos de vida.
} 
questiona se todos/as na periferia roubam, reafirmando um preconceito sobre os/as moradores/as locais. Em resposta, Will Salas ironicamente explicita que "isso é muito rico da sua parte".

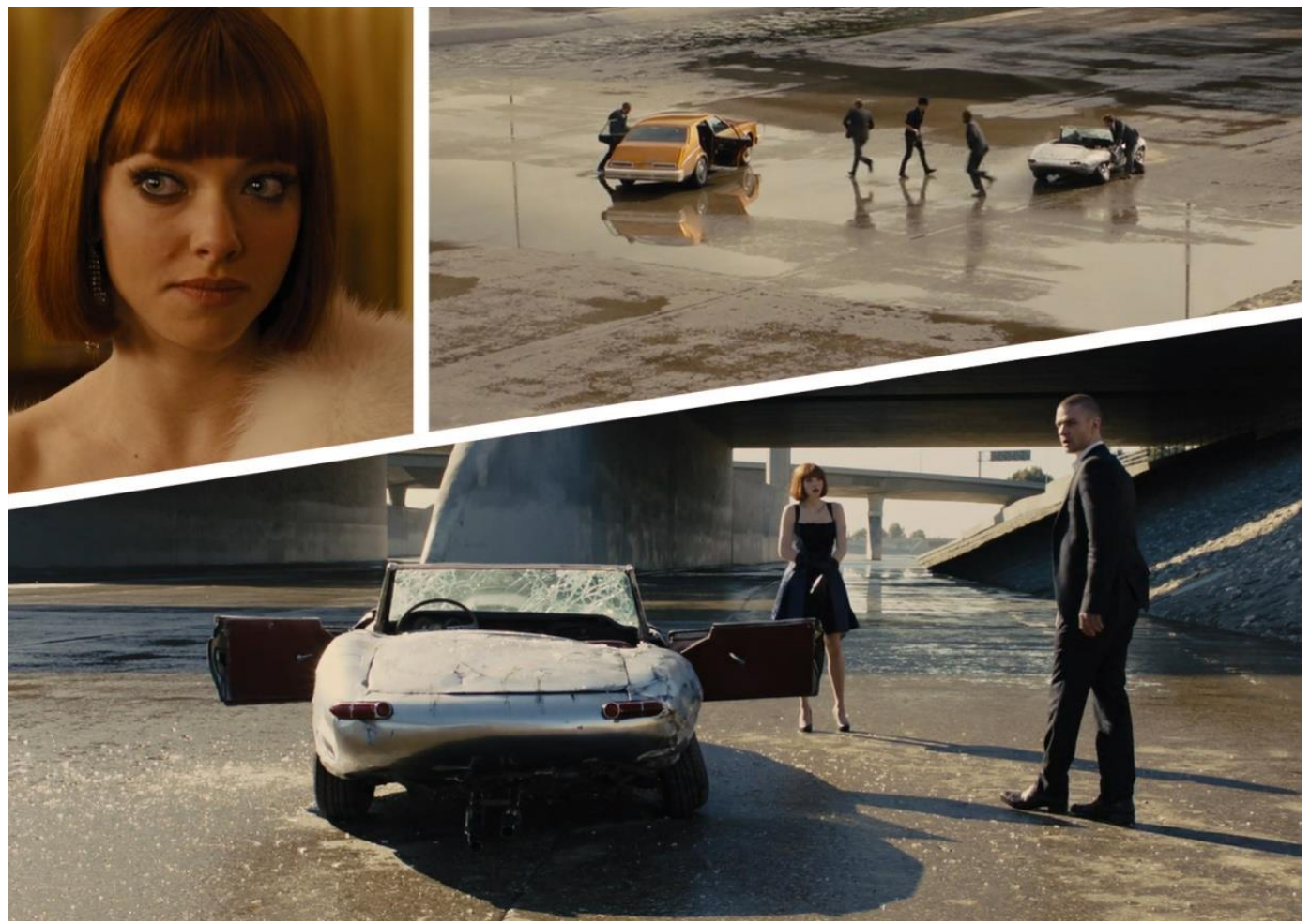

Figura.03: "Todos na periferia roubam?"

Fonte: Prints Screen capturados entre o 20' e 51' o do vídeo localizado no YouTube pelo link: <https://www.youtube.com/watch?v=1vQYroOViBk>. Acesso em 21 de setembro de 2015.

Após esse episódio, Will Salas divide seus poucos minutos de capital/tempo de vida com Sylvia Weis, que, após isso, coloca-se como uma integrante da zona periférica. Diante da consequência do sistema em que seu pai é influente, Sylvia Weis entende e, mais do que isso, sente na pele o sofrimento e dor que os/as pobres encontram para sobreviverem dia após dia. Em diálogo com Will Salas, Sylvia Weis questiona: "Se você tivesse muito ... tempo, você gastaria dando a outras pessoas?". Ao que ele responde: "Eu sempre tive um dia. De quanto tempo você precisa?". Após isso, juntamente com Will Salas, Sylvia Weis passa a compartilhar suas (poucas) horas de capital/tempo de vida e rouba uma filial do banco de sua própria família, invadindo-a com um automóvel, com o intuito de distribuir o capital/tempo de vida para os/as habitantes de Dayton - por quem passa a sentir empatia. Esta atitude reafirma o significado de mixofilia, expressado por Bauman (2007), pois a personagem muda sua perspectiva e postura em relação aos indivíduos que lhes são diferentes e demonstra interesse e solidariedade a eles. 0 conjunto de ações pode ser percebido na Figura.04. 


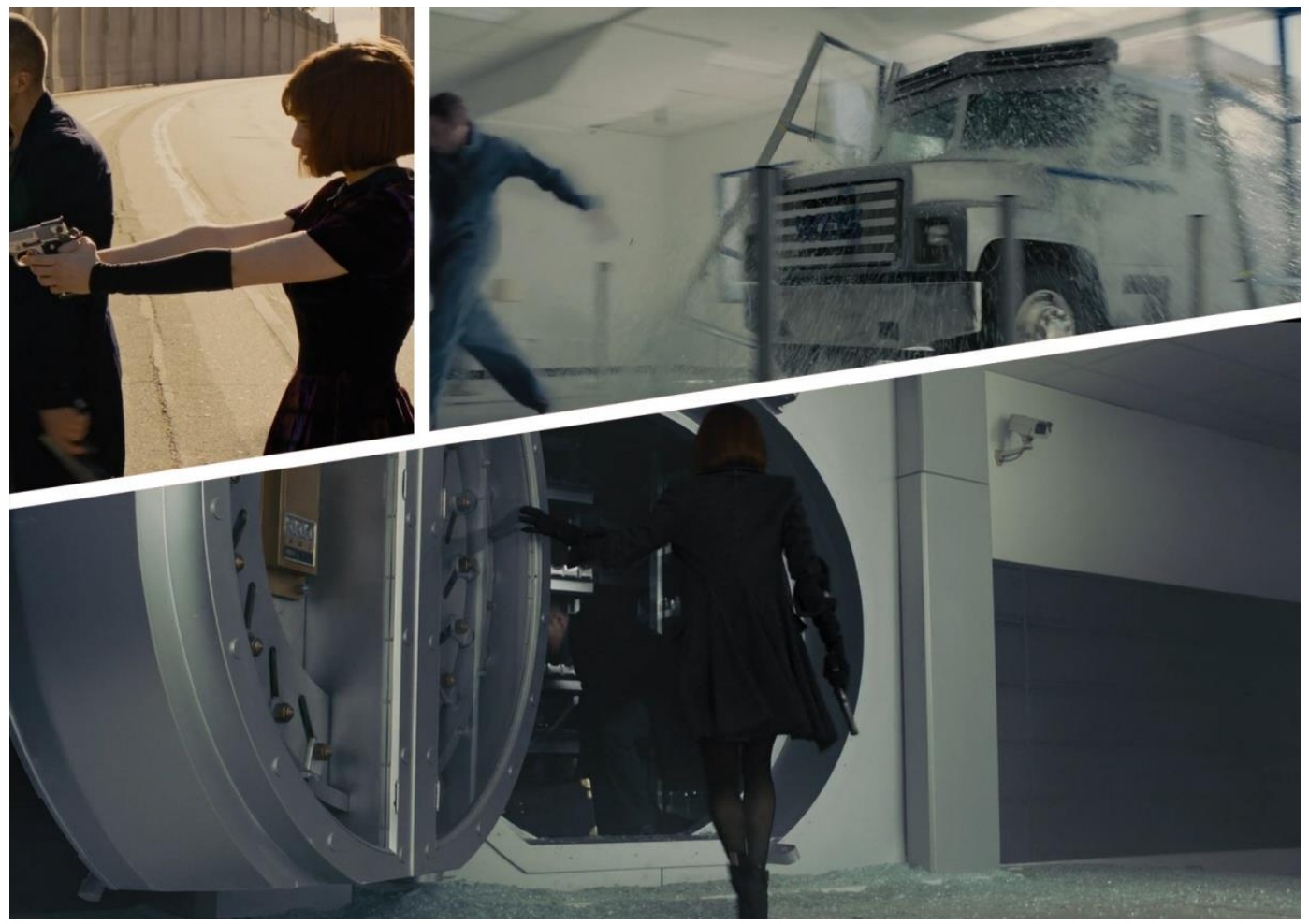

Figura.04: " De quanto tempo você precisa?"

Fonte: Prints Screen capturados entre o 66' e o 76' do vídeo localizado no YouTube pelo link: <https://www.youtube.com/watch?v=1vQYr0OViBk>. Acesso em 21 de setembro de 2015.

Tendo chegado a esse momento da narrativa de In Time (2011), analisamos que, quando Will Salas se deslocou ao encontro de New Greenwish, atravessando as fronteiras e pagando os "pedágios", imaginamos, inicialmente que está abandonando Dayton e seus/suas conterrâneos/as, haja vista que agora ele tem condições, capital/tempo de vida excedentes para fazer suas escolhas dentre as muitas opções de onde residir. Neste caso, estaria exercendo o que Hirschman (1979) denomina como Saída. A saída se materializa em ações, pensamentos e gestos de abandono, quando determinados membros, ou clientes, deixam organizações sociais por não estarem satisfeitos com o que elas Ihes oferecem.

Saída também implica buscar outras organizações, empresas e espaços, que sejam mais eficientes e conveniente com aquilo que procuramos. Conforme Vieira (2001, p.162) na saída, o indivíduo aproveita-se das opções para "[...] defender seu bem-estar ou para melhorar sua situação". É importante lembrar que, para exercer a saída, é necessário que se tenha condições de acessar as outras opções. Em outras palavras, antes de receber a doação de Henry Hamilton, Will Salas não poderia ter escolhido deixar Dayton, e consequentemente, exercer a saída.

Todavia, como pode ser percebido na Figura.04, as ações de Will Salas concorrem mais ao conceito de Voz, quando indivíduos explicitam sua "[...] insatisfação diretamente 
à direção, a uma autoridade à qual a direção esteja subordinada, ou através de protestos gerais, dirigidos a quem estiver interessado em ouvi-los" (HIRSCHMAN, 1979, p. 16). Ainda que saída e voz sejam conceitos desenvolvidos inicialmente para análises econômicas, conforme indica Hirschman (1979, p. 14) "[...] são aplicáveis não apenas a agente econômicos como as empresas, mas também a uma grande variedade de organizações e situações não econômicas", como em movimentos políticos e sociais, como protestos e pressões. Diferentemente da saída, solução silenciosa, caracterizada pela conveniência, pelo individualismo e pelo imediatismo, e cuja satisfação e resolução são temporárias, quando se pratica a voz, articula-se coletivamente, somando diferentes vozes, opiniões e críticas afim de operar politicamente. É por meio da voz, que os indivíduos poderão trabalhar na manutenção social e, com isso, adiar e diminuir as práticas de saída (VIEIRA, 2001).

Por fim, consideramos que as cenas finais do filme revelam que os/as moradores/as de Dayton, em sua maioria operários/as de fábricas, foram beneficiados/as pelo roubo organizado por Will Salas e Sylvia Weis, e que decidem atravessar as fronteiras que segregam as diferentes Zonas do Tempo. A Figura.05, ilustra o momento em que, na televisão, é feita uma transmissão ao vivo sobre a situação polêmica que permeia o país. Enquanto a voz feminina de uma repórter anuncia que em Dayton, há tanto capital/tempo de vida roubado em circulação, que as fábricas estão vazias, percebemos que os/as trabalhadores/as estão à rua. A reportagem ao vivo ainda transmite imagens das pessoas passando por túneis escuros de concreto na Zona do Tempo 04, a de New Greenwish, tendo ao fundo uma forte claridade evidenciando a continuação da estrada. A informação na parte inferior da tela destaca a frase " $A$ million years now in so many hands, (...)", que pode ser traduzida para, "Um milhão de anos agora em tantas mãos (...)" (Figura.05). 

time"

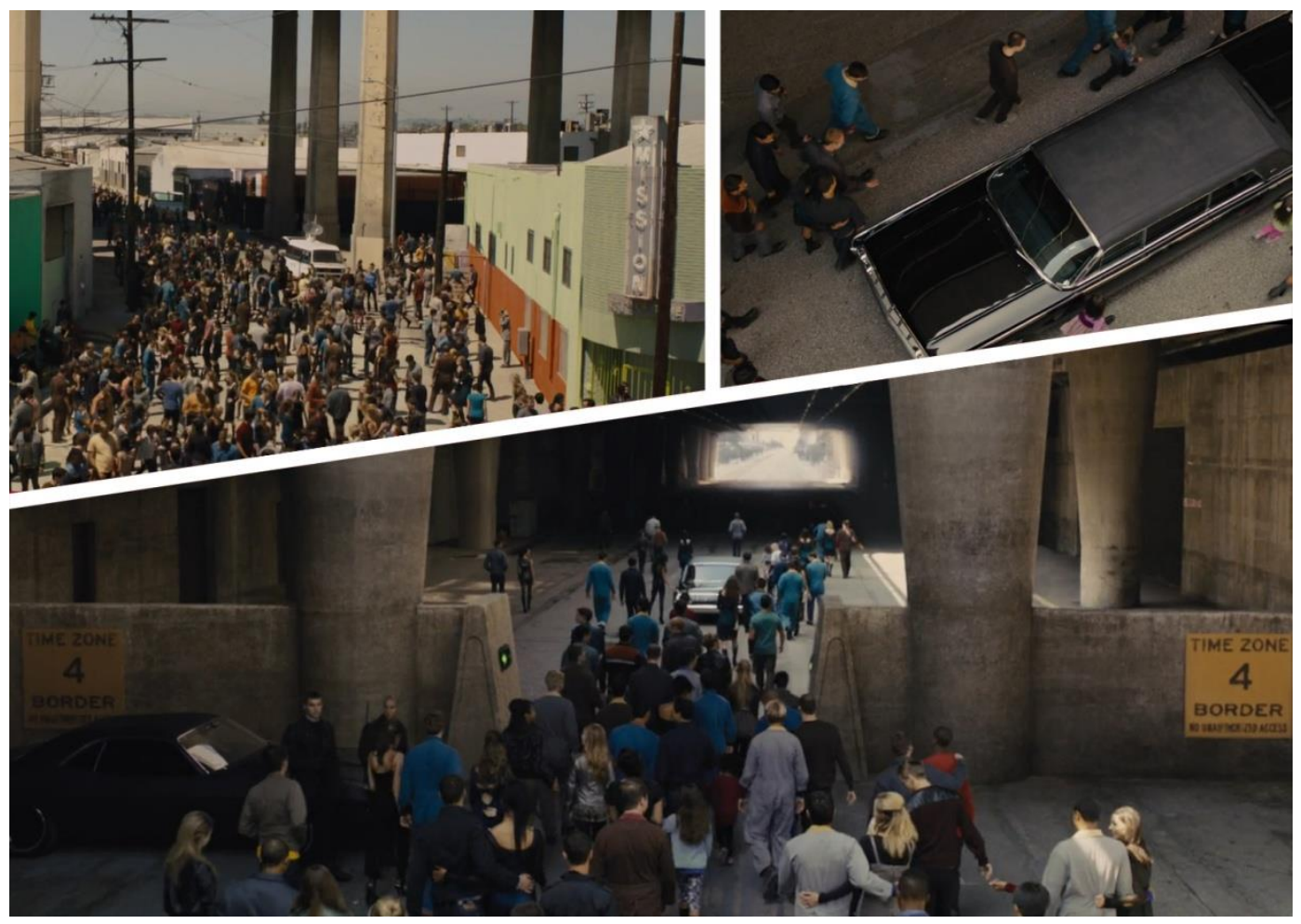

Figura.05: "Um milhão de anos agora em tantas mãos".

Fonte: Prints Screen capturados entre o 111' e o 114' do vídeo localizado no YouTube pelo link: <https://www.youtube.com/watch?v=1vQYrOOViBk>. Acesso em $21 \mathrm{de}$ setembro de 2015.

Esses trabalhadores e trabalhadoras que optam por sair da Zona Dayton nunca tiveram dinheiro/tempo de vida suficientes para ultrapassar as fronteiras, porque o preço é estrategicamente alto para não facilitar o livre acesso. É como se, até então, não tivessem condições mínimas para exercer aquilo ao que Hirschman (1979) denomina como saída. Como consequência disso, até esse momento essas pessoas estavam presas somente ao seu mundo ou aos guetos aos quais foram involuntariamente colocadas (BAUMAN, 2007). Agora com posse de dinheiro/tempo de vida, sentiram que podiam aproveitar dos benefícios e dos luxos que as outras pessoas tinham em excesso.

A cerca separa o "gueto voluntário" dos ricos e poderosos dos muitos guetos forçados dos pobres e excluídos. Para os integrantes do gueto voluntário, os outros guetos são espaços aos quais "nós não vamos". Para integrantes dos guetos involuntários, a área na qual estão confinados (por serem excluídos de outras) é o espaço "do qual não temos permissão de sair. (BAUMAN, 2007, p. 82)

No filme, parece-nos que, carentes do sentimento de lealdade, os moradores/as e trabalhadores/as de Dayton preferiram, ainda que temporariamente, fazer uso da saída a fazer uso da voz. É como se a Zona periférica, semelhantemente aos guetos involuntários (BAUMAN, 2007) operasse como espaço indesejado, inclusive, para os próprios/as habitantes. 
A narrativa do filme nos sugere que se 0 pequeno grupo com muito dinheiro/tempo de vida dividisse sua fortuna com os/as mais pobres, facilitaria o equilíbrio entre as forças e uma divisão mais simétrica entre os poderes. Apesar de haver resistência e vigilância para que o sistema permaneça favorecendo os/as mais ricos/as, há esperanças, já que aqui, metaforicamente, a porta de entrada de New Greenwish não representa apenas a ascensão financeira, mas a busca por espaços compartilhados entre indivíduos estranhos e iguais e oportunidades de verificar as dificuldades em desempenhar ações de manutenção política, que caracterizam a voz.

\section{Considerações finais}

Após discorrer sobre cinco cenas, compostas de 21 imagens retiradas do filme In Time (2011), aproximando-as dos conceitos de Bauman (2007; 2010), Bourdieu (1989; 2014) e Hirschman (1979), analisamos que o sistema econômico da ficção, semelhante ao de nossa sociedade contemporânea, não beneficia a todos/as. A igualdade só existe em teoria e o Estado insiste em ser omisso, quando não parcial em privilegiar apenas pequenos grupos hegemônicos, dificultando a possibilidade de os demais ascenderem socialmente. No filme, o sistema "quebra" se não houver consumo e mão de obra para garantirem a rapidez e descartabilidade características do consumismo. Conforme argumenta Schor (2009, p xvii) "a economia de mercado se assemelha a uma bicicleta". Enquanto se está em movimento, vai tudo bem e o equilíbrio é mantido. O problema se torna evidente quando se está parado. Tanto na economia, quanto na bicicleta, a diminuição e, em casos mais graves, a ausência de movimento, implicam "quedas".

Deste modo, em uma economia alicerçada no consumismo, a produtividade, o descarte, a distribuição assimétrica de bens e a dominação são estratégias que, semelhante a pedaladas de uma bicicleta, evitam ou pelo menos retardam as quedas. Além disso, quando se almeja ser produtivo, incentivam-se também ações e Políticas Públicas que favoreçam a compreensão do consumismo e da flexibilidade como predicativos intrínsecos (e quase naturalizados) aos indivíduos contemporâneos (MOMO, 2015).

Depois de conviver com a classe trabalhadora, a personagem Sylvia Weis sente empatia e procura ajudar os/as menos favorecidos/as pelo sistema, distribuindo e (com)partilhando o capital/tempo de vida, que até então, estava em posse de poucos/as. Em contrapartida, finalizando nossas considerações, levantamos reflexões quanto ao comportamento daqueles beneficiados pelas ações e iniciativas de Will Salas e Sylvia Weis. É possível que muitos/as trabalhadores/as, depois de conseguirem capital/tempo de tempo suficiente para usufruir dos bens de consumo proporcionados pela cidade de New Greenwish, poderiam exercitar a saída e esquecerem e abandonarem seus 
"Para que poucos usufruam muito, muitos não devem usufruir nada": movimentos de voz e saída no filme "in time"

conterrâneos? Em consecutivos movimentos de saída, egoísmo e conveniência, poderiam estes/as, antes dominados/as, passarem a se comportar como dominadores/as? Seria novamente prejudicial a essa população garantir a promessa de equilíbrio, quando a sociedade é moldada para o consumo e para o acúmulo de bens? Oferecer melhores condições de trabalho e educação seria um caminho mais apropriado do que tentar inverter a pirâmide da atual sociedade? Essas perguntas atuam como indícios de que discutir sobre predicativos da sociedade contemporânea globalizada cujo alicerce é estruturado sobre o capital e a cultura configura ações de pesquisa que não se encerram neste artigo e que evidenciam a necessidade de pensarmos em estratégias sociais e pedagógicas para problematizar as maneiras como nos posicionamos e somos posicionados/as no mundo.

\section{REFERÊNCIAS}

BALISCEI, João Paulo. Os artefatos visuais e suas pedagogias: Reflexões sobre o ensino de arte. 140 f. Dissertação (Mestrado em Educação) - Universidade Estadual de Maringá. Orientadora: Teresa Kazuko Teruya. Maringá, 2014.

BALISCEI, João Paulo; STEIN, Vinícius.Como olhamos e somos olhados Como olhamos e somos olhados pelas imagens? Estudos críticos dos artefatos da cultura visual. Revista Reflexão e Ação, Santa Cruz do Sul, v.23, n.1, p.251-275, jan./jun.2015.

BAUMAN, Z. Capitalismo parasitário. Tradução Eliana Aguiar - Rio de Janeiro: Jorge Zahar Ed., 2010.

BAUMAN, Z. Tempos líquidos. Tradução Carlos Alberto Medeiros - Rio de Janeiro: Jorge Zahar, 2007.

BOURDIEU, Pierre. O Poder Simbólico. Tradução Fernando Tomaz - Rio de Janeiro: Editora Bertrand Brasil S.A, 1989.

BOURDIEU, Pierre. A dominação masculina: a condição feminina e a violência simbólica. Tradução Maria Helena Kühner - Rio de Janeiro: BestBolso, 2014.

DONDIS, A. Donis.Sintaxe da Linguagem Visual. São Paulo: Martins Fontes, 2000.

EVANGELISTA, Olinda. Apontamentos para o trabalho com documentos de política educacional. Curso de Extensão, Universidade Estadual de Maringá, novembro de 2009..

HIRSCHMAN, Albert. Saída, voz e lealdade: reações ao declínio de firmas, organizações e estados. São Paulo: Perspectiva, 1979.

IN Time. Direção: Andrew Niccol. EUA: Regency Enterprises, New Regency Pictures, Strike Entertainment, 2011. arquivo digital.

KIRCHOF, E. R. WORTMAN, M. L. COSTA, M. V. Apontamentos à gusa de introdução. In: KIRCHOF, E. R. WORTMAN, M. L. COSTA, M. V. (Org.). Estudos Culturais \& Educação: contingências, articulações, aventuras e dispersões - Canoas: Ed. ULBRA, 2015, p. 7-20. 
MELO, Marcelo Paula de; FALLEIROS, Ialê. Reforma da aparelhagem estatal: Novas estratégias de legitimação social. In: NEVES, Lúcia Maria Wanderley (org.). A nova pedagogia da hegemonia. São Paulo: Xamã, 2005. p. 175-192.

MOMO, Mariangela. Infância e escola no espaço-tempo de consumo. In: KIRCHOF, E. R. WORTMAN, M. L. COSTA, M. V. (Org.). Estudos Culturais \& Educação: contingências, articulações, aventuras e dispersões - Canoas: Ed. ULBRA, 2015, p. 93-113.

OTT, Robert William. Ensinando crítica nos museus. In: BARBOSA, Ana Mae (Org.). Arteeducação: leituras no subsolo. São Paulo: Cortez, 2011. p. 113-141.

SCHOR, Juliet B. Nascidos para comprar: uma leitura essencial para orientarmos nossas crianças na era do consumismo. Tradução de Eloisa Helena de Souza Cabral . São Paulo: Editora Gente, 2009.

STEINBERG, Shirley R. Produzindo múltiplos sentidos - pesquisa com bricolagem e pedagogia cultural. In: KIRCHOF, Edgar Roberto; WORTMAN, Maria Lúcia; COSTA, Marisa Vorraber (org.). Estudos Culturais e educação: contingências, articulações, aventuras, dispersões. Canoas: Ed. ULBRA, 2015, p. 211-241.

VIEIRA, Ubirajara S. Resenha Crítica. Sociedade em debate. Pelotas, 7(2): 161-165, Agosto, 2001.

\footnotetext{
i Possui graduação em Artes Visuais pelo Centro Universitário de Maringá (2009); especialização em Arte-Educação (2010) e Educação Especial (2011) pelo Instituto de Estudos Avançados e Pós-Graduação; e Mestrado em Educação (2014) pela Universidade Estadual de Maringá. Atualmente é professor no curso de Artes Visuais na Universidade Estadual de Maringá e doutorando no Programa de Pós-Graduação em Educação da referida instituição. É membro do GEPAC - Grupo de Estudos e Pesquisas em Psicopedagogia, Aprendizagem e Cultura - e desenvolve pesquisas sobre Pedagogias Culturais, Cultura Visual, Ensino de Arte e Multiculturalismo.
}

ii possui graduação em Pedagogia pela Universidade Federal do Rio Grande do Sul (1979), mestrado em Educação pela Universidade Federal do Rio Grande do Sul (1989) e doutorado em Educação pela Universidade Estadual de Campinas (2002). Atualmente é professora adjunto da Universidade Estadual de Maringá. Tem experiência na área de Educação, com ênfase em Formação de Conceitos, atuando principalmente nos seguintes temas: cultura, educação, representações sociais, ensino-aprendizagem, construtivismo e intervenção pedagógica.

iii Graduado em Arte-Educação pela Universidade Estadual do Centro-Oeste (2011). Especialista em Educação Especial pelo Instituto de Estudos Avançados em Pós Graduação (2012). Especialista em Teoria Histórico-Cultural pelo departamento de Psicologia da Universidade Estadual de Maringá (2014). Mestre em Educação pelo Programa de Pós-Graduação em Educação da Universidade Estadual de Maringá (2014). Doutorando em Educação pelo Programa de Pós-Graduação em Educação da Universidade Estadual de Maringá (2016). Integra o Grupo de Pesquisa e Estudos em Educação Infantil - GEEI. É professor da Universidade Estadual de Maringá. Pesquisa sobre ensino de Arte, Educação Estética e Educação Infantil.

Enviado em: 05 de maio de 2016.

Aprovado em: 13 de julho de 2016.

Revista Digital do LAV - Santa Maria - vol. 9, n. 2, p. 181 - 201. - mai./ago. 2016 ISSN 1983 - 7348 http://dx.doi.org/10.5902/1983734822296 